\title{
NUTRIÇÃO E PRODUTIVIDADE DO ALGODOEIRO EM FUNÇÃO DE DOSES DE NÍQUEL E REGULADOR DE CRESCIMENTO
}

\section{Raiana Crepaldi de Faria Nocchi ${ }^{1 *}$, Enes Furlani Junior ${ }^{2}$, Noemi Cristina de Souza Vieira ${ }^{3}$,} Amanda Pereira Paixão ${ }^{3}$, Dayane Bortoloto da Silva ${ }^{3}$, Mariana Moreira Melero ${ }^{3}$, Mirella dos Santos Pereira ${ }^{4}$

\footnotetext{
${ }^{1}$ Doutoranda do Programa de Pós-Graduação em Agronomia da Universidade Estadual de Maringá (UEM), Maringá- PR. *E-mail do autor correspondente: raianacdef@hotmail.com

${ }^{2}$ Docente do Departamento de Fitotecnia, Tecnologia de Alimentos e Sócio Economia da Universidade Estadual Paulista (UNESP), Faculdade de Engenharia, Ilha Solteira-SP.

${ }^{3}$ Doutoranda do Programa de Pós-Graduação em Agronomia da Universidade Estadual Paulista (UNESP), Faculdade de Engenharia, Ilha Solteira-SP.

${ }^{4}$ Mestra em Agronomia pela Universidade Estadual Paulista (UNESP), Faculdade de Engenharia, Ilha SolteiraSP.
}

Recebido: 30/11/2018; Aceito: 26/03/2020

RESUMO: Buscando o aumento da produtividade do algodoeiro, várias pesquisas vêm sendo realizadas com o uso de reguladores de crescimento e novas fontes nutricionais, com a finalidade de acelerar o desenvolvimento da cultura. $\mathrm{O}$ objetivo do trabalho foi avaliar o efeito da adubação foliar com doses de níquel associado ou não a aplicação do regulador de crescimento no algodoeiro cultivado em condições edafoclimáticas do cerrado. $\mathrm{O}$ experimento foi conduzido na Fazenda de Ensino, Pesquisa e Extensão (FEPE), da Faculdade de Engenharia de Ilha Solteira - UNESP, localizada no município de Selvíria-MS. O delineamento experimental utilizado foi o de blocos ao acaso em esquema fatorial $5 \times 2$, com quatro repetições. A aplicação do níquel foi via foliar e parcelada em três aplicações 47, 60 e 75 dias após a emergência (DAE) nas doses $\left(0,50,150,300\right.$ e $\left.400 \mathrm{~g} \mathrm{ha}^{-1}\right)$. O regulador de crescimento utilizado foi o cloreto de mepiquat aplicado uma única vez, aos 70 DAE. O aumento das doses de níquel não influenciou os teores dos macronutrientes, inclusive de nitrogênio, porém, a utilização do regulador de crescimento juntamente com a dose de $400 \mathrm{~g}$ $\mathrm{ha}^{-1}$ de Ni ocasionou o menor acúmulo dos teores foliares de $\mathrm{Ca}^{+2} \mathrm{e} \mathrm{Mg}^{+2}$. A aplicação das doses de $\mathrm{Ni}$ elevaram a concentração deste nutriente nas folhas do algodoeiro. A produtividade de algodão em caroço e de fibra não foram influenciadas pelo aumento das doses de níquel. No entanto, para massa de 20 capulhos, doses acima de $200 \mathrm{~g} \mathrm{ha}^{-1}$ se mostraram prejudiciais. A aplicação do regulador de crescimento diminuiu a massa de 20 capulhos, porcentagem e produtividade de fibra do algodoeiro.

Palavras-chave: Gossypium hirsutum. Adubação. Cloreto de mepiquat. Sulfato de níquel.

\section{NUTRITION AND YIELD OF COTTON IN FUNCTION OF NICKEL DOSES AND GROWTH REGULATOR}

ABSTRACT: In order to increase cotton yield, several researches have been carried out with the use of growth regulators and new nutritional sources, in order to accelerate the 
development of the crop. The objective of this work was to evaluate the effect of foliar fertilization with doses of nickel with or without the application of the growth regulator in the cotton cultivated under edaphoclimatic conditions of the cerrado. The experiment was carried out at the Fazenda de Ensino, Pesquisa e Extensão (FEPE), at the Faculty of Engineering of Ilha Solteira - UNESP, located in the municipality of Selvíria-MS. The experimental design was a randomized block design in a $5 \times 2$ factorial scheme, with four replicates. The application of nickel was via foliar and split in three applications 47, 60 and 75 days after emergence (DAE) at doses $\left(0,50,150,300\right.$ and $\left.400 \mathrm{~g} \mathrm{ha}^{-1}\right)$. The growth regulator used was once-applied mepiquat chloride at 70 DAE. The increase of the nickel doses did not influence the macronutrients contents, including nitrogen, but the use of the growth regulator together with the dose of $400 \mathrm{~g} \mathrm{ha}^{-1}$ of $\mathrm{Ni}$ resulted in a lower accumulation foliar contents of the $\mathrm{Ca}^{+2}$ and $\mathrm{Mg}^{+2}$. The application of $\mathrm{Ni}$ doses increased the concentration of this nutrient in the leaves of cotton. Cotton and fiber cotton yields were not influenced by increasing nickel doses. However, for mass of 20 boll, doses above $200 \mathrm{~g} \mathrm{ha}^{-1}$ have been shown to be harmful. The application of the growth regulator decreased the mass of 20 boll, percentage and productivity of cotton fiber.

Key words: Gossypium hirsutum. Fertilizing. Mepiquat chloride. Nickel sulfate.

\section{INTRODUÇÃO}

A cotonicultura brasileira segue em crescente expansão e vem se destacando atualmente como uma atividade agrícola promissora, apresentando excelentes resultados técnicos e econômicos. Nos últimos anos, o Brasil tem se mantido entre os cinco maiores produtores mundiais, ao lado de países como China, Índia, EUA e Paquistão. Em termos de produtividade em sequeiro, o Brasil ocupa o primeiro lugar (ASSOCIAÇÃO BRASILEIRA DOS PRODUTORES DE ALGODÃO - ABRAPA, 2018).

Na safra, 2017/2018 estima-se que serão produzidos 2,9 milhões de toneladas de algodão em pluma (COMPANHIA NACIONAL DE ABASTECIMENTO- CONAB, 2018). A Região Centro-Oeste é hoje a principal produtora de algodão no país, com área plantada de aproximadamente em 840,8 mil hectares (ABRAPA, 2018).

Na busca da melhoria dos atuais níveis de produtividade e redução dos custos de produção da cultura do algodoeiro no Brasil, novas tecnologias vêm sendo incorporadas ao sistema de produção dessa malvácea. Entre as novas tecnologias em estudo, a manipulação da arquitetura das plantas do algodoeiro com a utilização de biorreguladores e novas fontes nutricionais são estratégias agronômicas para o incremento da produtividade.

Dentre os fatores responsáveis pela produtividade do algodoeiro, destaca-se uma adubação equilibrada. O nitrogênio está entre os nutrientes mais requeridos pela cultura, sendo considerado um fator importante para a obtenção de elevadas produtividades. Estudos que contemplem mecanismos capazes de aumentar a disponibilidade desse elemento no sistema solo é essencial para o desenvolvimento tecnológico da cultura. Em termos nutricionais, o níquel (Ni) foi identificado como elemento essencial, por ser cofator da enzima urease, ou seja, é componente da enzima, apresentando dois átomos de Ni em sua 
composição estrutural. A enzima urease por sua vez desdobra a ureia em amônia e dióxido de carbono, a escassez deste elemento pode ocasionar acúmulo de ureia nas folhas, causando efeito fitotóxico (MACEDO, 2016; REIS et al., 2014; SILVA, 2016). Devido sua importância para o aproveitamento do nitrogênio pelas plantas do algodoeiro, desperta-se o interesse de elucidar a relação do níquel com o metabolismo do nitrogênio.

Em regiões com condições climáticas favoráveis como de cerrado, tem-se verificado excessivo crescimento vegetativo do algodoeiro, condição esta que pode ocasionar sua queda produtiva, sendo assim, a utilização de reguladores de crescimento se faz necessária para obtenção de plantas mais produtivas e com porte adequado à colheita mecanizada (TEIXEIRA et al., 2008). O cloreto de mepiquat (cloreto 1,1-dimetil piperidíneo) é um dos reguladores de crescimento mais empregado no cultivo do algodoeiro. Esse produto interfere na biossíntese do ácido giberélico, inibindo-o, o que resulta em redução do crescimento, em razão da menor elongação celular (LAMAS, 2001). De acordo com Reddy et al. (1996), esse regulador é um produto sistêmico, absorvido principalmente pelas partes verdes da planta e translocado de forma ascendente e descendente, pelo xilema e floema, de maneira uniforme.

O efeito da aplicação do cloreto de mepiquat no algodoeiro é principalmente através da redução do crescimento vegetativo, isto é, diminuição da altura, do tamanho dos ramos vegetativos e reprodutivos, comprimento dos internódios e número de folhas; o que gera o aumento da retenção de frutos nas primeiras posições dos ramos frutíferos; a abertura precoce dos frutos com antecipação da colheita, que por sua vez pode contribuir para reduzir o ataque de pragas tardias, maior uniformização do estande de cultivo, melhorando a eficiência dos tratos culturais e de colheita (LAMAS; ATHAYDE, 1999; LAMAS, 2001).

Atualmente para a cultura do algodoeiro não existem publicações sobre a adubação com sulfato de níquel e sua interação com a aplicação do regulador de crescimento, no entanto, esse conhecimento é fundamental para a utilização foliar desse nutriente. Sendo assim, o objetivo do trabalho foi avaliar o efeito da adubação foliar com doses de sulfato de níquel associado ou não a aplicação do regulador de crescimento na nutrição e produtividade do algodoeiro cultivado em condições edafoclimáticas do cerrado.

\section{MATERIAL E MÉTODOS}

O experimento foi conduzido na área experimental da Fazenda de Ensino, Pesquisa e Extensão da Faculdade de Engenharia de Ilha Solteira, FEIS/UNESP, localizada no município de Selvíria-MS, com coordenadas geográficas 20²2' de Latitude Sul e 51²2' de Longitude Oeste e com altitude média de $335 \mathrm{~m}$. O solo da área experimental é classificado como latossolo vermelho distrófico típico muito argiloso (EMPRESA BRASILEIRA DE PESQUISA AGROPECUÁRIA - EMBRAPA, 2013). O clima da região, segundo a classificação de Köppen, é do tipo Aw, definido como tropical úmido com estação chuvosa no verão e seca no inverno. Os dados climatológicos obtidos durante o período experimental estão relacionados na Figura 1. 


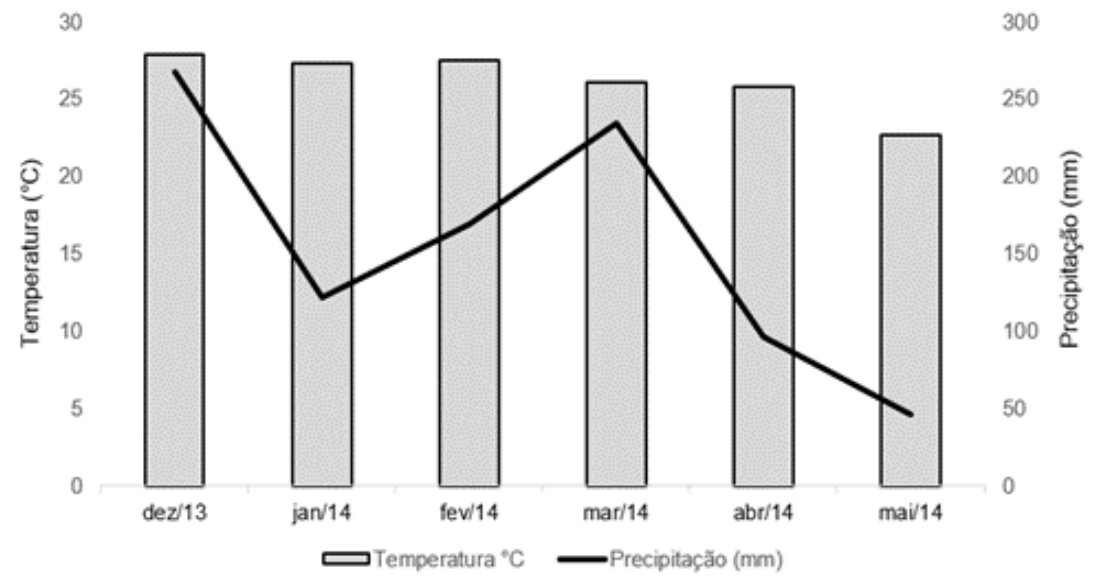

Figura 1. Média mensal de temperatura $\left({ }^{\circ} \mathrm{C}\right)$ e precipitação pluvial $(\mathrm{mm})$, no período de dezembro a maio no ano agrícola 2013/14. Selvíria-MS. Monthly mean temperature $\left({ }^{\circ} \mathrm{C}\right)$ and precipitation ( $\mathrm{mm}$ ), from December to May in the agricultural year 2013/14. Selvíria-MS.

Fonte: Laboratório de hidráulica e irrigação da UNESP- Ilha Solteira (2014). Hydraulic laboratory and irrigation of UNESP - Ilha Solteira (2014).

O preparo do solo consistiu de correção da acidez através da calagem e uma aração seguida de gradagem para incorporação dos restos culturais. A instalação do experimento foi em dezembro/2013 através da semeadura do cultivar de algodão FM 975 WS ${ }^{\circledR}$, adubado na base com $350 \mathrm{~kg} \mathrm{ha}^{-1}$ da formulação 08-28-16, fornecidos de acordo com a análise química do solo (Tabela 1) e as recomendações para a cultura de Silva e Raij (1997).

Tabela 1. Características químicas do solo da área experimental, nos anos de 2013/2014, no município de Selvíria-MS. Chemical soil characteristics of the experimental area, in the years of 2013/2014, in the municipality of Selviria-MS.

\begin{tabular}{|c|c|c|c|c|c|c|c|c|c|c|}
\hline \multirow[t]{2}{*}{ Ano } & M.O & $\mathbf{p H}$ & $\mathbf{P}$ & $\mathbf{K}$ & $\mathbf{C a}$ & Mg & $\mathbf{H}+\mathbf{A l}$ & Al & CTC & \multirow{2}{*}{$\begin{array}{l}\mathbf{V} \\
(\%)\end{array}$} \\
\hline & $\mathrm{g} \mathrm{dm}^{-3}$ & $\mathrm{CaCl}_{2}$ & $\mathrm{mg} \mathrm{dm}{ }^{-3}$ & \multicolumn{6}{|c|}{$\begin{array}{ll}1 & 1 \\
- & 1 \\
- & 1\end{array}$} & \\
\hline 2013 & 23 & 5,1 & 34 & 2,8 & 23 & 17 & 28 & 0 & 70,8 & 60 \\
\hline 2014 & 21 & 5,3 & 29 & 3,5 & 38 & 22 & 29 & 0 & 92,5 & 69 \\
\hline
\end{tabular}

Fonte: Laboratório de fertilidade do solo da UNESP- Ilha Solteira (2013/2014). Soil fertility laboratory of UNESP - Ilha Solteira (2013/2014).

Para a adubação de cobertura foi utilizado $60 \mathrm{~kg} \mathrm{ha}^{-1}$ de $\mathrm{N}$ divididas igualmente em duas aplicações aos 35 e 65 DAE. Na primeira aplicação a fonte utilizada foi uréia $(45 \% \mathrm{~N})$ e na segunda utilizou-se a fórmula 20-00-20.

O delineamento experimental foi o de blocos casualizados em esquema fatorial 5 x 2 com quatro repetições. Os tratamentos foram constituídos pela combinação de cinco doses de níquel $\left(0,50,150,300\right.$ e $\left.400 \mathrm{~g} \mathrm{ha}^{-1}\right)$ e ausência ou presença de cloreto de mepiquat. A fonte de níquel utilizada foi sulfato de níquel aplicado através de pulverização foliar aos 47, 60 e 75 DAE. O regulador de crescimento PIX HC (cloreto de mepiquat $250 \mathrm{~g} \mathrm{~L}^{-1}$ ) foi aplicado uma única vez, na dose de $0,2 \mathrm{~L} \mathrm{ha}^{-1}$ aos $70 \mathrm{DAE}$.

As características agronômicas foram avaliadas em dez plantas escolhidas ao acaso em cada parcela. Os atributos analisados referentes ao crescimento, foram avaliados aos 83 e 104 DAE, sendo elas altura $(\mathrm{cm})$, diâmetro de caule $(\mathrm{mm})$ e contagem do número de nós a partir do colo da planta até a última ramificação do meristema apical. 
As características nutricionais do algodoeiro foram avaliadas aos 80 DAE, mediante a coleta de folhas localizada na quinta posição da haste principal, conforme recomendado por Silva (1999). Após a coleta, as folhas foram submetidas à secagem em estufa com circulação forçada de ar na temperatura de $65^{\circ} \mathrm{C}$ até atingirem peso constante, posteriormente, trituradas em moinho de facas tipo Willey e encaminhadas ao laboratório de análise de tecido vegetal do Departamento de Fitotecnia da FEIS/Unesp/Ilha Solteira, onde seguiram a metodologia relatada por Malavolta et al. (1997) para a determinação dos teores de fósforo (P), potássio $(\mathrm{K})$, cálcio $(\mathrm{Ca})$, magnésio $(\mathrm{Mg})$ e enxofre $(\mathrm{S})$ obtidos através da digestão nitro-perclórica e, o teor de níquel (Ni), por digestão de via seca, em mufla, a $550^{\circ} \mathrm{C}$. Para determinação do teor de nitrogênio $(\mathrm{N})$ o material foi submetido à digestão sulfúrica.

A colheita foi realizada manualmente aos 150 DAE e a produção do algodão foi avaliada através das variáveis: massa de 20 capulhos (g) colhidos aleatoriamente no terço médio das plantas e pesados com auxílio de balança digital; produtividade do algodão em caroço $\left(\mathrm{kg} \mathrm{ha}^{-1}\right)$ estimada através da colheita das linhas centrais da parcela; porcentagem de fibra (\%) por meio das amostras da massa de 20 capulhos, submetidas a separação mecânica da fibra e semente por desfibradora pertencente ao Instituto Agronômico de Campinas (IAC) e posteriormente, realizada a pesagem de cada componente e efetuado os cálculos pela fórmula: (peso de fibra/peso fibra + semente)*100; e produtividade de fibra $\left(\mathrm{kg} \mathrm{ha}^{-1}\right)$ calculada da seguinte forma: (produtividade de algodão em caroço estimada) * (porcentagem de fibra/100).

Os dados obtidos foram submetidos à análise de variância através do teste $\mathrm{F}$ e comparação de médias pelo teste de Tukey e Regressão polinomial á significância de $10 \%$. O software estatístico utilizado foi o SISVAR 5.1 (FERREIRA, 2000).

\section{RESULTADOS E DISCUSSÃO}

Na Tabela 2 constam os resultados da análise dos parâmetros de altura, diâmetro de caule e número de nós do algodoeiro avaliados aos 83 e 104 DAE. Na avaliação aos 83 DAE não houve efeito significativo das doses de níquel para as variáveis altura, diâmetro de caule e número de nós. Segundo Teixeira et al. (2005) a disponibilidade de Ni para as plantas é maior em solos com pH menor que 5,5. O presente estudo foi instalado no cerrado, onde os solos são tipicamente ácidos, com faixa de $\mathrm{pH}$ favorável para a disponibilidade de alguns elementos metálicos, dentre eles o níquel (Tabela 1). As doses de níquel não demonstraram ganhos em termos de crescimento, provavelmente devido à existência de níveis iniciais desse elemento no solo suficiente para suprir as necessidades das plantas.

Na avaliação aos 104 DAE, verificou-se que não houve diferença significativa entre os parâmetros analisados em relação a aplicação das doses de níquel e o regulador de crescimento. Os resultados do presente trabalho sobre o uso do regulador de crescimento são divergentes com demais estudos que demonstram a sua utilização em algodoeiro é capaz de diminuir o porte da planta. Vários fatores podem ter ocasionado esta resposta, dentre elas o porte da planta, dosagem pequena aplicada e o não parcelamento da aplicação. Com relação à dose utilizada, segundo Wallace et al. (1993), o parcelamento das aplicações de cloreto de mepiquat apresenta melhor efeito em relação à aplicação única sobre a altura de plantas, 
número de nós e comprimento dos internódios. De acordo com Cia et al. (1984), nas cultivares que apresentaram excessivo crescimento vegetativo, os efeitos do cloreto de mepiquat foram benéficos, por outro lado, nas cultivares de porte baixo o efeito do produto não foi significativo.

Tabela 2. Médias de altura (cm), Diâmetro de caule $(\mathrm{mm})$ e número de nós do algodoeiro c.v. FM 975 WS $^{\circledR}$ aos 83 e 104 DAE. Selvíria-MS, 2013/2014. Mean height (cm), stem diameter (mm) and number of nodes of cotton c.v. FM $975 \mathrm{WS}^{\circledR}$ at 83 and 104 DAE. Selvíria-MS, $2013 / 2014$.

\begin{tabular}{|c|c|c|c|c|c|c|}
\hline \multicolumn{7}{|c|}{$\mathbf{p}>\mathbf{F}$} \\
\hline \multirow[t]{2}{*}{ FV } & \multicolumn{3}{|c|}{83 D.A.E } & \multicolumn{3}{|c|}{ 104 D.A.E } \\
\hline & Altura $(\mathrm{cm})$ & $\begin{array}{c}\text { Diâmetro } \\
(\mathrm{mm})\end{array}$ & $\mathrm{n}^{\circ}$ de nós & $\begin{array}{l}\text { Altura } \\
(\mathrm{cm})\end{array}$ & $\begin{array}{c}\text { Diâmetro } \\
(\mathrm{mm})\end{array}$ & $\mathrm{n}^{\circ}$ de nós \\
\hline Doses de Ni (Ni) & 0,72 & 0,83 & 0,62 & 0,71 & 0,39 & 0,22 \\
\hline Regulados (Reg) & 0,84 & 0,69 & 0,28 & 0,24 & 0,10 & 0,63 \\
\hline Ni X Reg & 0,19 & 0,19 & 0,75 & 0,48 & 0,48 & 0,77 \\
\hline $\mathrm{CV}(\%)$ & 9,76 & 15,16 & 11,76 & 6,83 & 7,59 & 6,72 \\
\hline \multicolumn{7}{|c|}{ Doses de Ni $\left(\mathrm{g} \mathrm{ha}^{-1}\right)$} \\
\hline 0 & 91,53 & 1,41 & 15,37 & 107,68 & 1,97 & 19,71 \\
\hline 50 & 91,80 & 1,33 & 16,87 & 108,00 & 1,96 & 19,68 \\
\hline 150 & 92,34 & 1,44 & 16,00 & 108,63 & 2,06 & 19,61 \\
\hline 300 & 93,14 & 1,35 & 16,00 & 109,58 & 2,09 & 19,52 \\
\hline 400 & 93,68 & 1,37 & 15,87 & 110,22 & 2,00 & 19,46 \\
\hline $\mathrm{p}>\mathrm{F}(\mathrm{L})$ & 0,60 & 0,75 & 0,89 & 0,425 & 0,29 & 0,65 \\
\hline $\mathrm{p}>\mathrm{F}(\mathrm{Q})$ & 0,88 & 0,83 & 0,56 & 0,85 & 0,14 & 0,26 \\
\hline $\mathrm{r}^{2}(\mathrm{~L})$ & 0,13 & 0,06 & 0,06 & 0,30 & 0,26 & 0,03 \\
\hline $\mathrm{R}^{2}(\mathrm{Q})$ & 0,14 & 0,10 & 0,13 & 0,32 & 0,80 & 0,24 \\
\hline \multicolumn{7}{|c|}{ Regulador de crescimento } \\
\hline Com & $91,31 \mathrm{a}$ & $1,39 \mathrm{a}$ & $16,35 \mathrm{a}$ & $107,43 \mathrm{a}$ & $2,06 \mathrm{a}$ & $19,50 \mathrm{a}$ \\
\hline Sem & $93,68 \mathrm{a}$ & $1,37 \mathrm{a}$ & $15,70 \mathrm{a}$ & $110,22 \mathrm{a}$ & $1,98 \mathrm{a}$ & $19,70 \mathrm{a}$ \\
\hline D.M.S & 3,88 & 0,11 & 1,01 & 4,01 & 0,82 & 0,70 \\
\hline
\end{tabular}

* Valores seguidos por letras iguais na coluna, não diferem entre si pelo teste de Tukey ao nível de $10 \%$ de probabilidade. * Values followed by equal letters in the column, do not differ by Tukey test at the 10\% probability level.

Fonte: Autoria própria. Own authorship.

Os dados obtidos para os teores de macronutrientes foliares (Tabela 3) demonstraram que a aplicação das doses de níquel não proporcionou alterações significativas nas concentrações foliares de N, P, Ca, Mg e S. Apesar do Ni ser um elemento de importância para o metabolismo do nitrogênio nas plantas, sendo parte integrante da metaloenzima uréase, que catalisa a degradação da ureia em dióxido de carbono e amônia (DIXON et al., 1975), no presente trabalho não houve influência significativa no acúmulo de nitrogênio na parte aérea do algodoeiro. Assim como, Rodak (2014) observou que a aplicação de doses de Ni não resultou em efeito significativo na concentração de $\mathrm{N}$ foliar das plantas de soja, cultivadas em dois solos de texturas franco arenoso e muito argiloso. 
Tabela 3. Teores foliares de macronutrientes e níquel em algodoeiro c.v. FM $975 \mathrm{WS}^{\circledR}$ após aplicação de doses de Níquel e Regulador de crescimento. Selvíria-MS, 2013/2014. Leaf content of macronutrients and nickel in cotton c.v. FM 975 WS ${ }^{\circledR}$ after application of doses of Nickel and Growth Regulator. Selvíria-MS, 2013/2014.

\begin{tabular}{|c|c|c|c|c|c|c|c|}
\hline \multirow[t]{2}{*}{ Tratamentos } & $\mathbf{N}$ & $\mathbf{P}$ & $\mathbf{K}$ & $\mathbf{C a}$ & Mg & $\mathbf{S}$ & \multirow{2}{*}{$\frac{\mathbf{N i}}{\mathrm{mg} \mathrm{kg}^{-1}}$} \\
\hline & \multicolumn{6}{|c|}{ 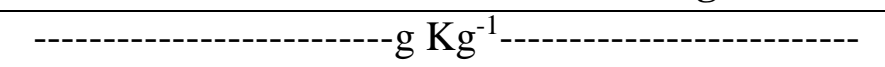 } & \\
\hline Doses de $\mathrm{Ni}$ & 0,50 & 0,84 & 0,77 & 0,82 & 0,27 & 0,36 & $0,01^{*}$ \\
\hline Regulador & 0,87 & 0,78 & 0,85 & 0,40 & 0,84 & 0,91 & 0,46 \\
\hline Ni X Reg & 0,30 & 0,90 & 0,18 & $0,04^{*}$ & $0,01^{*}$ & 0,20 & 0,93 \\
\hline $\mathrm{CV}(\%)$ & 11,42 & 10,27 & 14,80 & 10,97 & 11,59 & 18,75 & 31,56 \\
\hline \multicolumn{8}{|c|}{ Doses de Ni $\left(\mathrm{g} \mathrm{ha}^{-1}\right)$} \\
\hline 0 & 46,71 & 5,24 & 14,46 & 32,87 & 7,00 & 7,23 & 12,50 \\
\hline 50 & 47,09 & 5,45 & 14,78 & 32,68 & 6,90 & 6,66 & 11,25 \\
\hline 150 & 50,17 & 5,35 & 15,40 & 32,09 & 7,68 & 6,10 & 10,00 \\
\hline 300 & 45,36 & 5,37 & 14,78 & 31,03 & 6,90 & 6,65 & 15,00 \\
\hline 400 & 47,67 & 5,55 & 14,00 & 31,65 & 6,93 & 7,25 & 18,75 \\
\hline $\mathrm{p}>\mathrm{F}(\mathrm{L})$ & 0,87 & 0,43 & 0,60 & 0,30 & 0,73 & 0,774 & 0,01 \\
\hline $\mathrm{p}>\mathrm{F}(\mathrm{Q})$ & 0,57 & 0,83 & 0,23 & 0,66 & 0,17 & 0,05 & 0,01 \\
\hline $\mathrm{r}^{2}(\mathrm{~L})$ & 0,07 & 0,45 & 0,15 & 0,75 & 0,02 & 0,01 & 0,67 \\
\hline $\mathrm{R}^{2}(\mathrm{Q})$ & 0,10 & 0,48 & 0,96 & 0,88 & 0,38 & 0,93 & 0,96 \\
\hline \multicolumn{8}{|c|}{ Regulador de crescimento } \\
\hline Com & $47,28 \mathrm{a}$ & $5,41 \mathrm{a}$ & $14,62 \mathrm{a}$ & $31,60 \mathrm{a}$ & $7,11 \mathrm{a}$ & $6,76 \mathrm{a}$ & $13,00 \mathrm{a}$ \\
\hline Sem & $47,54 \mathrm{a}$ & $5,37 \mathrm{a}$ & $14,75 \mathrm{a}$ & $32,53 \mathrm{a}$ & $7,06 \mathrm{a}$ & $6,80 \mathrm{a}$ & $14,00 \mathrm{a}$ \\
\hline DMS (10\%) & 2,91 & 0,29 & 1,17 & 1,89 & 0,44 & 0,68 & 2,29 \\
\hline
\end{tabular}

Valores seguidos por letras iguais na coluna, não diferem entre si pelo teste de Tukey ao nível de $10 \%$ de probabilidade. * Values followed by equal letters in the column, do not differ by Tukey test at the 10\% probability level.

Fonte: Autoria própria. Own authorship.

A não-detecção do efeito significativo das doses de $\mathrm{Ni}$ nos teores foliares de $\mathrm{N}$ no algodoeiro, pode ser explicada principalmente pelo efeito diluição, em que as plantas apresentam maior crescimento e desenvolvimento. A época de amostragem das folhas foi realizada aos 80 DAE, neste período, grande aporte de $\mathrm{N}$ foliar é remobilizado para estruturas reprodutivas, consequentemente, observa-se diminuição na concentração de $\mathrm{N}$ foliar.

Para os tratamentos com e sem a utilização do regulador de crescimento, não houve efeitos significativos sobre a absorção dos macronutrientes. No entanto houve interação entre os fatores (Ni x Reg) para os teores foliares de cálcio (Figura 2. A e B) e magnésio (Figura 2 C e D).

Os teores foliares de $\mathrm{Ni}$ no algodoeiro responderam positivamente às doses de $\mathrm{Ni}$ aplicadas (Tabela 3), o que indica que a concentração desse nutriente na planta depende do fornecimento do elemento. $\mathrm{O}$ acúmulo de $\mathrm{Ni}$ foliar variou entre 12,5 e $18,75 \mathrm{mg} \mathrm{kg}^{-1}$. Apesar do aumento da concentração desse nutriente nas folhas, não foi constatado diferença significativa das doses de Ni nos componentes de produção do algodoeiro (Tabela 4). Do mesmo modo, Alovisi et al (2011) verificaram que a aplicação foliar de doses de sulfato de 
níquel em soja, aumentaram os teores de Ni foliar, entretanto, não acarretaram incremento na produção da cultura.

Paiva et al. (2003) relataram a elevação dos teores de Ni nas folhas novas de ipê-roxo, foi resultado do incremento das doses de $\mathrm{Ni}$ na solução nutritiva, demonstrando que este elemento é móvel na planta. Efeito este encontrado neste estudo, ou seja, observou-se aumento da concentração foliar de Ni com o incremento das doses de Ni aplicadas via foliar (Tabela 3).
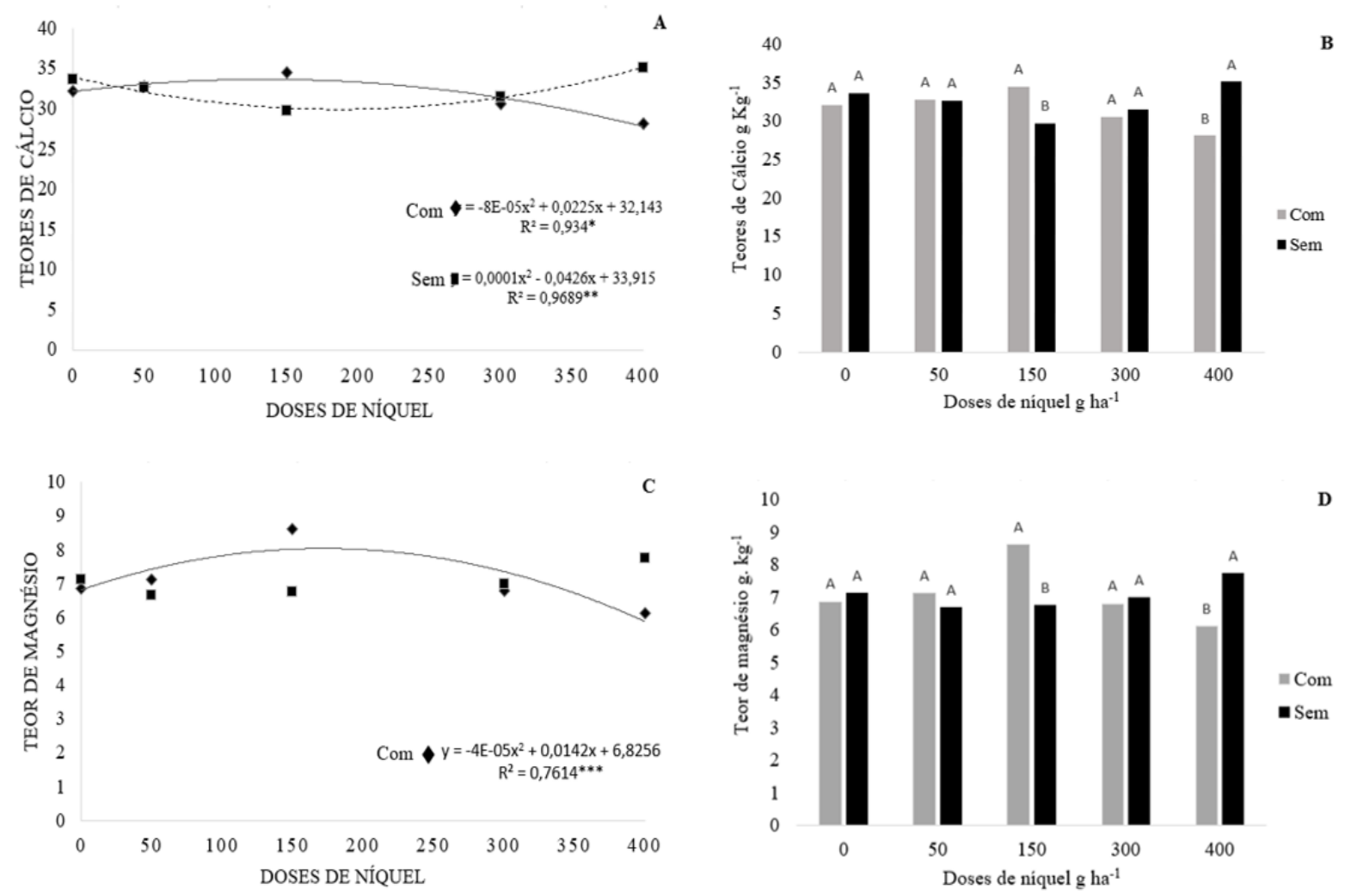

$(*)$ significativo a $10 \% ;(* *)$ significativo a $5 \% ;(* *)$ significativo a $1 \%$ de probabilidade. $(*)$ significant to $10 \% ;(* *)$ significant at $5 \% ;(* * *)$ significant at $1 \%$ probability.

Figura 2. Teores de Cálcio (A e B) e magnésio (C e D), de plantas de algodoeiro aos 80 DAE em função de doses de níquel com ou sem aplicação do regulador de crescimento. Calcium (A and $B$ ) and magnesium ( $C$ and $D$ ) contents of cotton plants at 80 DAE as a function of nickel doses with or without growth regulator application.

Fonte: Autoria própria. Own authorship.

O desdobramento do efeito dos tratamentos para o teor de cálcio foliar por meio da análise de regressão polinomial evidenciou o ajuste quadrático para as doses de níquel na presença ou ausência do regulador de crescimento (Figura 2. A). Para os teores de magnésio foliar houve um ajuste quadrático para as doses de níquel com a presença do regulador de crescimento, entretanto, para a ausência da aplicação do regulador de crescimento não houve ajuste dos dados ao modelo de regressão calculado (Figura 2.C). O acúmulo máximo de magnésio na presença do regulador de crescimento estimado pelo modelo da equação que 
melhor se ajustou aos dados foi na dose de 173,57 $\mathrm{g} \mathrm{ha}^{-1} \mathrm{Ni}$, apresentando um teor foliar de 9,30 $\mathrm{g} \mathrm{Kg}^{-1}$ de magnésio.

$\mathrm{Na}$ dose de 150 e $400 \mathrm{~g} \mathrm{ha}^{-1}$ de níquel houve diferença significativa com relação ao

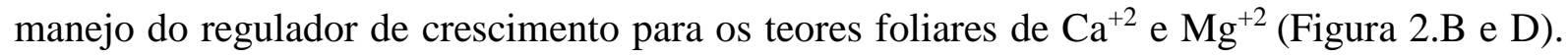
As plantas que receberam a aplicação de $150 \mathrm{~g} \mathrm{ha}^{-1}$ de níquel e o regulador de crescimento, apresentaram maiores teores foliares dos nutrientes $\mathrm{Ca}^{+2} \mathrm{e} \mathrm{Mg}^{+2}$, quando comparadas com o tratamento sem o uso do cloreto de mepiquat. Porém, plantas que receberam a aplicação da dose de $400 \mathrm{~g} \mathrm{ha}^{-1}$ de níquel acrescidas do regulador obtiveram menor acúmulo de cálcio (Figura 2.B) e magnésio (Figura 2.D) quando comparadas com a não utilização deste produto. A dose máxima de níquel aplicada no presente trabalho pode ter influenciado nos teores de cálcio e magnésio, visto que, de acordo com Marschner (1995), cátions bivalentes como o

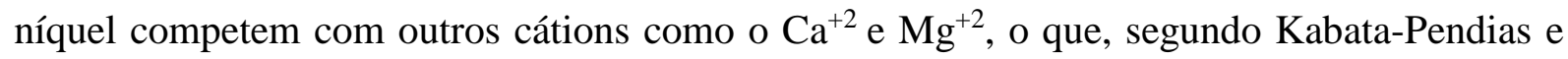
Pendias (1984), muitas vezes é caracterizado como antagonismo. No entanto os resultados, em termos de efeito da presença de níquel sobre a absorção de cálcio e de magnésio, têm sido contraditórios. Paiva, Carvalho e Siqueira (2002) concluíram que o teor de $\mathrm{Ca}^{+2}$ e de $\mathrm{Mg}^{+2} \mathrm{em}$ mudas de cedro é reduzido com a aplicação de Ni, porém, em aveia, Crooke e Inkson (1955) relataram que o níquel reduziu a absorção de $\mathrm{Mg}^{+2}$, mas aumentou a absorção de $\mathrm{Ca}^{+2}$.

Na Tabela 4 constam os resultados dos componentes de produção da cultura do algodoeiro no ano agrícola 2013/14. Verificou-se que para a massa média de 20 capulhos, porcentagem de fibra e a produtividade de fibra foram significativamente influenciadas pela aplicação de cloreto de mepiquat, porém o índice de produtividade de algodão em caroço não.

A utilização do regulador não proporcionou acréscimo na produtividade de algodão, fator este que pode ser atribuído a baixa dosagem empregada do produto comercial e a única aplicação durante todo ciclo da cultura. Isso pode ter ocorrido porque aplicações parceladas de cloreto de mepiquat proporcionam maior redução na altura das plantas, do número de nós, do comprimento dos internódios e maior retenção de frutos, em comparação com a aplicação única (WALLACE et al., 1993). De acordo com Teixeira et al. (2008) avaliando a produtividade do algodoeiro submetido a cloreto de mepiquat e doses de nitrogênio, concluíram que a aplicação do regulador na dose $50 \mathrm{~g} \mathrm{ha}^{-1}$ parcelado três vezes ao longo do ciclo da cultura, promoveu acréscimos de rendimento produtivo de $12 \%$ quando comparado a testemunha.

Não foi observado qualquer efeito de interação entre regulador de crescimento x doses de Ni (Tabela 4). As doses de níquel não incrementaram significativamente a produtividade de algodão em caroço, porcentagem de fibra e produtividade da fibra. A massa de 20 capulhos foi afetada pelas doses crescentes de níquel. Dessa forma, observou-se através de regressão polinomial, o ponto de mínimo na dose de $300 \mathrm{~g} \mathrm{ha}^{-1}$ de níquel, ou seja, pode ter ocorrido pequena toxidez, acarretando a diminuição da massa de 20 capulhos, embora as plantas não tenham apresentado sintoma visual (Figura 3). Altos teores de Ni nos tecidos vegetais podem inibir a fotossíntese e a respiração (PAIVA et al. 2003), fator este que pode ter induzido menor desenvolvimento de capulhos do presente trabalho. 
Tabela 4. Produtividade do algodoeiro cv. FM 975WS ${ }^{\circledR}$ aos 150 dias após a emergência. Selvíria - MS, ano agrícola 2013/14. Productivity of cotton cv. FM 975WS ${ }^{\circledR}$ at 150 days after the emergency. Selvíria - MS, agricultural year 2013/14.

\begin{tabular}{|c|c|c|c|c|}
\hline \multicolumn{5}{|c|}{$\mathbf{p}>\mathbf{F}$} \\
\hline FV & $\begin{array}{l}\text { Produtividade de } \\
\text { algodão em } \\
\text { caroço }\left(\mathrm{kg} \mathrm{ha}^{-1}\right)\end{array}$ & $\begin{array}{l}\text { Massa de } 20 \\
\text { capulhos (g) }\end{array}$ & $\begin{array}{l}\text { Porcentagem } \\
\text { de fibra }(\%)\end{array}$ & $\begin{array}{l}\text { Produtividade de } \\
\text { fibra }\left(\mathrm{kg} \mathrm{ha}^{-1}\right)\end{array}$ \\
\hline Doses de $\mathrm{Ni}(\mathrm{Ni})$ & 0,71 & 0,31 & 0,79 & 0,57 \\
\hline Regulados (Reg) & 0,65 & $0,09 *$ & $0,05^{*}$ & $0,03 *$ \\
\hline Ni X Reg & 0,40 & 0,19 & 0,12 & 0,16 \\
\hline $\mathrm{CV}(\%)$ & 20,55 & 6,65 & 6,62 & 20,10 \\
\hline \multicolumn{5}{|c|}{ Doses de Ni $\left(\mathrm{g} \mathrm{ha}^{-1}\right)$} \\
\hline 0 & 2640 & 1,11 & 0,46 & 1219 \\
\hline 50 & 2966 & 1,11 & 0,47 & 1400 \\
\hline 150 & 2922 & 1,11 & 0,45 & 1338 \\
\hline 300 & 2924 & 1,05 & 0,45 & 1325 \\
\hline 400 & 3045 & 1,07 & 0,46 & 1410 \\
\hline $\mathrm{p}>\mathrm{F}(\mathrm{L})$ & 0,31 & 0,09 & 0,59 & 0,18 \\
\hline $\mathrm{p}>\mathrm{F}(\mathrm{Q})$ & 0,71 & 0,83 & 0,58 & 0,42 \\
\hline $\mathrm{r}^{2}(\mathrm{~L})$ & 0,49 & 0,59 & 0,17 & 0,08 \\
\hline $\mathrm{R}^{2}(\mathrm{Q})$ & 0,55 & 0,60 & 0,36 & 0,20 \\
\hline
\end{tabular}

\section{Regulador de crescimento}

\begin{tabular}{lcccc}
\hline Com & $2857 \mathrm{a}$ & $1,07 \mathrm{~b}$ & $0,45 \mathrm{~b}$ & $1291 \mathrm{~b}$ \\
Sem & $2942 \mathrm{a}$ & $1,11 \mathrm{a}$ & $0,47 \mathrm{a}$ & $1388 \mathrm{a}$ \\
D.M.S & 320 & 0,03 & 0,01 & 5,12
\end{tabular}

*Valores seguidos por letras iguais na coluna, não diferem entre si pelo teste de Tukey ao nível de $10 \%$ de probabilidade. * Values followed by equal letters in the column, do not differ by Tukey test at the 10\% probability level.

Fonte: Autoria própria. Own authorship.

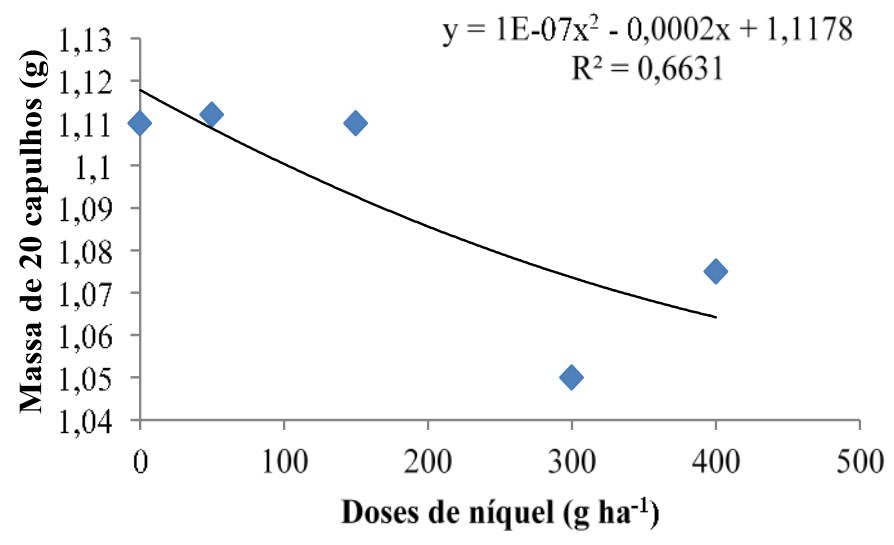

Figura 3. Massa de 20 capulhos (g) em função dos tratamentos com doses de níquel. Mass of 20 boll $(g)$ as a function of the treatments with doses of nickel.

Fonte: Autoria própria. Own authorship. 


\section{CONCLUSÃO}

O aumento das doses de níquel não influenciou os teores dos macronutrientes, inclusive de nitrogênio, porém, a utilização do regulador de crescimento juntamente com a dose de 400

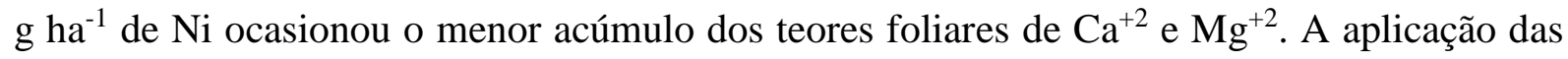
doses de Ni elevaram a concentração deste nutriente nas folhas do algodoeiro.

A produtividade de algodão em caroço e de fibra não foram afetadas pelo aumento das doses de níquel. No entanto, para massa de 20 capulhos, doses acima de $200 \mathrm{~g} \mathrm{ha}^{-1}$ se mostraram prejudiciais.

A aplicação do regulador de crescimento diminuiu a massa de 20 capulhos, porcentagem e produtividade de fibra do algodoeiro.

\section{AGRADECIMENTOS}

A CAPES pelo apoio financeiro concedido, através de bolsas de estudo.

\section{REFERÊNCIAS BIBLIOGRÁFICAS}

ALOVISI, A. M. T.; MAGRI, J.; DUTRA, J. E.; MAGRI, E.; SANTOS, M. J. G.; ALOSIVI, A. A. Adubação foliar com sulfato de níquel na cultura da soja. Ensaios e Ciência: Ciências Biológicas, Agrárias e da Saúde. Londrina, v. 15, n. 2, p.25-32, 2011.

ASSOCIAÇÃO BRASILEIRA DOS PRODUTORES DE ALGODÃO - ABRAPA. Algodão no Brasil. Brasília, DF, 2018. Disponível em: http://www.abrapa.com.br/Paginas/dados/algodao-no-brasil.aspx. Acesso em: 01 ago. 2018.

CIA, E.; CARVAlHO, L. H.; KONDO, J. I.; FUZATTO, M. G.; BORTOLETTO, N.; GALlO, P. B.; CRUZ, L. S. P.; SABINO, N. P.; PETTINELLI JÚNIOR, A.; MARTINS, A. L. M.; SILVEIRA, J. C. O. Efeito do cloreto de clorocolina e cloreto de mepiquat na cultura do algodão (Gossypium hirsutun L.). Planta Daninha, Campinas, v. 7, n. 2, p.23-36, 1984.

COMPANHIA NACIONAL DE ABASTECIMENTO - CONAB. Acompanhamento da safra brasileira de grãos: safra 2017/18: oitavo levantamento. Brasília, DF, 2018. v. 8, p.1145. Disponível em: https://www.conab.gov.br/info-agro/safras/graos. Acesso em: 01 ago. 2018.

CROOKE, W. M.; INKSON, R. H. E. The relationship between nickel toxicity and major nutrient supply. Plant and Soil, Dordrecht, v. 6, n. 1, p.1-15, 1955.

DIXON, N. E.; GAZZOLA, C.; BLAKELEY, R. L.; ZERNER, B. Jack bean uréase (EC 3.5.1.5). A metalloenzyme. A simple biological role for nickel? Journal of the American Chemical Society, Easton, v. 97, n. 14, p.4131-4133, 1975.

EMPRESA BRASILEIRA DE PESQUISA AGROPECUÁRIA - EMBRAPA. Sistema brasileiro de classificação de solos. 3. ed. rev. ampl. Brasília: Embrapa, 2013. 353 p. 
FERREIRA, D. F. Análises estatísticas por meio do Sisvar para Windows versão 4.0. In: REUNIÃO ANUAL DA REGIÃO BRASILEIRA DA SOCIEDADE INTERNACIONAL DE BIOMETRIA, 45, 2000, São Carlos. Anais [....] São Carlos: UFSCar, 2000. p. 255-258. Disponível em: www.dex.ufla.br/ danielff/softwares.htm. Acesso em: 01 ago. 2018.

KABATA-PENDIAS, A.; PENDIAS, H. Trace elements in soils and plants. Boca Raton: CRC, 1984.315 p.

KLUCAS, R. V.; HANUS, F. J; RUSSELL, S. A.; EVANS, H. J. Nickel, a micronutrient for hydrogen dependent growth of Rhizobium japonicum and for expression of urease activity in soybean leaves. Proceedings of the National Academy of Sciences of USA, New York, v. 80, p.2253-2257, 1983.

LAMAS, F. M.; ATHAYDE, M. L. F. Efeito do cloreto de mepiquat e do thidiazuron sobre algumas características das sementes do algodoeiro. Pesquisa Agropecuária Brasileira, Brasília, v. 34, n. 11, p. 2015-2019, 1999.

LAMAS, F. M. Estudo comparativo entre cloreto de mepiquat e cloreto de chlormequat aplicados no algodoeiro. Pesquisa Agropecuária Brasileira, Brasília, v. 36, n. 2, p.265-272, 2001.

MACEDO, F. G. Disponibilidade de Ni no sistema solo-planta: efeito de doses e saturações por bases. 2016. 119 f. Tese (Doutorado em Ciências) - Centro de Energia Nuclear na Agricultura, Universidade de São Paulo, Piracicaba, 2016.

MALAVOLTA, E.; VITTI, G. C.; OLIVEIRA, S. A. Avaliação do estado nutricional das plantas: princípios e aplicações. 2. ed. Piracicaba: POTAFOS, 1997. 319 p.

MARSCHNER, H. Mineral nutrition of higher plants. 2. ed. London: Academic Press, $1995.889 \mathrm{p}$.

PAIVA, H. N.; CARVALHO, J. G.; SIQUEIRA, J. O. Teor de nutrientes em mudas de cedro (Cedrela fissilis Vell.) Submetidas a doses crescentes de níquel, em Solução nutritiva. Revista Árvore, Viçosa, v. 26, n. 3, p.279- 284, 2002.

PAIVA, H. N.; CARVALHO, J. G.; SIQUEIRA, J. O.; FERNANDES, A. R.; MIRANDA, J. R. P. Efeito da aplicação de doses crescentes de níquel sobre o teor e o conteúdo de nutrientes em mudas de ipê-roxo (Tabebuia impetiginosa (Mart) Standley). Scientia Forestalis, Piracicaba, v. 32, n. 63, p.158-166, 2003.

REDDY, A. R.; REDDY, K. R.; HODGES, H. F. Mepiquat chloride (PIX) induced changes in photosynthesis and growth of cotton. Plant Growth Regulation, Dordrecht, v. 20, n. 3, p.179-183, 1996.

REIS, A. R.; RODAK, B. W.; PUTTI, F. F.; MORAES, M. F. Papel fisiológico do níquel: essencialidade e toxidez em plantas. Informações Agronômicas, Piracicaba, n. 147, p.10-24. 2014.

Disponível

em: http://www.ipni.net/publication/iabrasil.nsf/0/0A37B421DA0EA5F383257D660046D009/\$FI LE/Page10-24- 147.pdf. Acesso em: 16 set. 2019. 
RODAK, B. W. Níquel em solos e na cultura da soja. 2014. 88 p. Dissertação (Mestrado em ciências) - Universidade Federal do Paraná, Curitiba, 2014.

SILVA, N. M.; RAIJ, B. van. Fibrosas. In: RAIJ, B. van; CANTARELLA, H.; QUAGGIO, J. A.; FURLANI, A. M. C. (ed.). Recomendações de adubação e calagem para o Estado de São Paulo. 2. ed. Campinas: Instituto Agronômico/Fundação IAC, 1997. cap. 16, p. 107-111. (Boletim Técnico, 100).

SILVA, N. M. Nutrição mineral e adubação do algodoeiro no Brasil. In: CIA, E.; FREIRE, E. C.; SANTOS, W. J. Cultura do Algodoeiro. Piracicaba: POTAFÓS, 1999. p. 5792.

SILVA, I. C. Crescimento e produtividade do algodoeiro em função da aplicação de nitrogênio e níquel. 2016. 73 p. Dissertação (Mestrado em Agronomia) - Faculdade de Engenharia, Universidade Estadual Paulista, 2016.

TEIXEIRA, S. T.; MELO, W. J.; SILVA, E. T. Heavy metals in a degraded soil treated with sludge from water treatment plant. Scientia Agricola, Piracicaba, v. 62, n. 5, p.498-501, 2005.

TEIXEIRA, I. R.; KIKUTI, H.; BORÉM, A. Crescimento e produtividade de algodoeiro submetido a cloreto de mepiquat e doses de nitrogênio. Bragantia, Campinas, v. 67, n. 4, p.891-897, 2008.

WALlACE, T. P.; SNIPES, C. E.; WHITE, B. W. Effects of single and multiple applications of mepiquat chloride on Mississippi cotton. Starkville: MSU, 1993. 5 p. 